\title{
The prediction of $\mathrm{COOH}$ functionalized carbon nanotube application in melphalan drug delivery
}

\author{
Hadi Lari, Ali Morsali, Mohammad Momen Heravi \\ Department of Chemistry, Mashhad Branch, Islamic Azad University, Mashhad, Iran \\ hadilari1359@yahoo.com, almorsali@yahoo.com,drmh45@yahoo.com
}

PACS 78.67.n; 78.67.Ch

DOI 10.17586/2220-8054-2019-10-4-438-446

\begin{abstract}
Using quantum chemical calculations, noncovalent functionalization of melphalan drug on the surface of functionalized carbon nanotube (NT) have been examined. Quantum molecular descriptors of noncovalent interactions were investigated. It was concluded that binding of drug melphalan into $\mathrm{COOH}$-functionalized NT (FNT) is exothermic and makes the system stable. Comparison between FNT and COCl functionalized NT $\left(\mathrm{F}^{\prime} \mathrm{NT}\right.$ ) showed that FNT has more binding energy and may act as a carrier for drug delivery (if the noncovalent functionalization is desired). The $\mathrm{OH}$ and $\mathrm{NH}_{2}$ groups of melphalan may bond to $\mathrm{Cl}\left(\mathrm{COCl}\right.$ mechanism) and $\mathrm{COOH}\left(\mathrm{COOH}\right.$ mechanism) of $\mathrm{F}^{\prime} \mathrm{NT}$ and FNT, respectively. Therefore, four mechanisms for the covalent functionalization have been investigated. The transition states of four pathways were optimized and activation parameters were evaluated. The high barriers of $\mathrm{COOH}$ pathway are greater than those of $\mathrm{COCl}$ pathway and therefore $\mathrm{F}^{\prime} \mathrm{NT}$ is suitable carrier for covalent functionalization.
\end{abstract}

Keywords: Carbon nanotube, density functional theory, functionalization, melphalan, quantum descriptors.

Received: 14 May 2019

Revised: 28 June 2019

\section{Introduction}

Despite all efforts to overcome cancer, the old approaches through chemotherapy cause side effects such as vomiting, heart disease, hair loss and etc. [1,2]. In recent years, the use of targeted methods for drug delivery has been felt [3-6]. For this purpose, organic compounds such as dendrimers [7], drug-polymer conjugates [8] and liposomes [9] and inorganic nanoparticles, such as gold NPs [10], iron oxide NPs [11,12], silica NPs [13] have been exploited.

Experimental and theoretical studies have recently focused on carbon-based nanoparticles, such as carbon nanotubes and graphene, for drug delivery [14-21]. With a unique set of mechanical, electrical and chemical properties [22-29], carbon nanotubes have many applications in chemical pharmaceutical researches [30-33].

In spite of some deficiencies such as low solubility in aqueous solutions and high toxicity [34-36], carbon nanotubes have been highly regarded in drug delivery due to good cell penetration qualities and high drug loading [37-39]. Using nanotubes as the carrier molecules, lower doses of anticancer drugs are needed, resulting in reduced side effects of the medicine [40-42]. Functionalized carbon nanotubes were used as carriers for different anticancer drugs such as platinum (IV) [43], 6-mercaptopurine [44], doxorubicin [45,46], paclitaxel [47], Methotrexate [48], gemcitabine [49], camptothecin [50], tamoxifen [51], oridonin [52], sorafenib [53], soyasapogenol [54] and etc. Melphalan or 4-[bis(2Chloroethyl)amino]-L-phenylalanine is an alkylating agent which has anticancer activities and is extremely effective in the treatment of tumors such as multiple myeloma [55,56].

Quantum computing is a powerful tool for analyzing drug delivery systems [57-64]. In this work, quantum chemical calculations were used to study the covalent and noncovalent adsorption of the exterior surface of $\mathrm{COOH}$ functionalized carbon nanotube (FNT) with melphalan drug. Noncovalent functionalization is more commonly used to carry medicine, but in many cases, such as hydroxycamptothecin, doxorubicin, pirarubicin, platinol, methotrexate, tamoxifen and thalidomide, covalent functionalization has been used [65]. The predictions made in this way can help researchers build and use targeted anticancer drugs and reduce the process of trial and error in the laboratory.

\section{Computational details}

GAUSSIAN 09 package [66] has been utilized for the optimization of all configurations in gas and solution phases at UB3LYP/6-31G(d,p). Polarized continuum model (PCM) was employed to consider the implicit solvent effects $[67,68]$. For the optimization of the molecular configurations, the standard convergence criteria were utilized. All degrees of freedom were optimized for all species. The transition states were confirmed to have only one imaginary frequency of the Hessian. In addition, zero-point corrections were taken into account to obtain the activation energy. 
COOH functionalized armchair $(5,5)$ single wall carbon nanotube (FNT) comprising 114 atoms $(10 \AA)$ was considered as FNT model. Unrestricted method (U in UB3LYP) is used for molecules with unpaired electrons such as FNT model.

Quantum molecular descriptors may be used to evaluate chemical reactivity and stability. The global hardness $(\eta)$ demonstrates the resistance of one particle against the modification in its electronic configuration:

$$
\eta=\frac{I-A}{2},
$$

where $I=-E_{H O M O}$ and $A=-E_{L U M O}$ are the ionization potential and the electron affinity, respectively. The electrophilicity index $(\omega)$ [69] is evaluated by

$$
\omega=\frac{(I+A)^{2}}{8 \eta}
$$

\section{Results and discussion}

Melphalan (M) is an anticancer molecule with $\mathrm{NH}_{2}, \mathrm{OH}$ and $\mathrm{Cl}$ groups as represented in Fig. 1. The optimized geometries of $\mathrm{M}, \mathrm{COOH}$ functionalized carbon nanotube $(\mathrm{FNT})$ and $\mathrm{COCl}$ functionalized carbon nanotube $\left(\mathrm{F}^{\prime} \mathrm{NT}\right)$ in aqueous solution have been shown in Fig. 1.

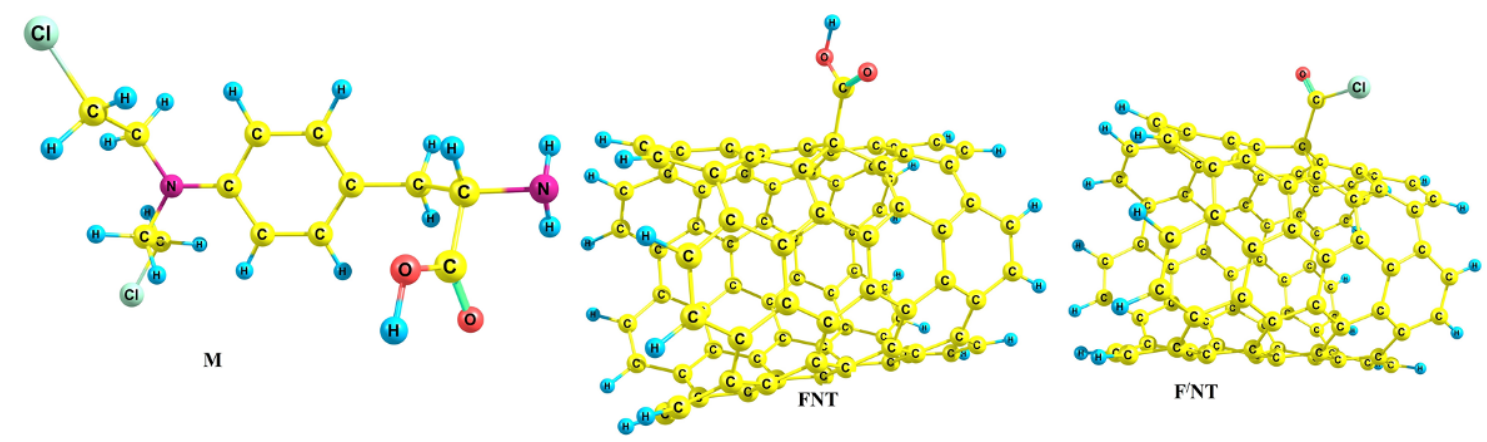

FIG. 1. Optimized geometries of $\mathrm{M}, \mathrm{FNT}$ and $\mathrm{F}^{\prime} \mathrm{NT}$

The hydrogen bond interactions between $\mathrm{M}$ and $\mathrm{FNT}$ or $\mathrm{F}^{\prime} \mathrm{NT}$ occur via $\mathrm{NH}_{2}, \mathrm{OH}$ and $\mathrm{Cl}$ groups. These five configurations have been illustrated in Figs. 2 and 3, namely, FNT/M1-3R and F'NT/M1-2R.

The binding energies $(\Delta E)$ of $\mathrm{M}$ to FNT (in water) and $\mathrm{F}^{\prime} \mathrm{NT}$ (in DMF) were calculated using equation (3) and represented in Table 1:

$$
\Delta E=E_{F N T\left(F^{\prime} N T\right) / M 1-3 R}-\left(E_{F N T\left(F^{\prime} N T\right)}+E_{M}\right) .
$$

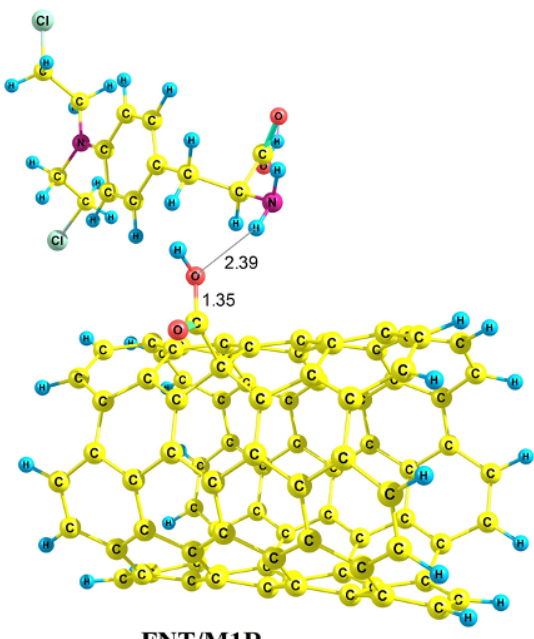

FNT/M1R

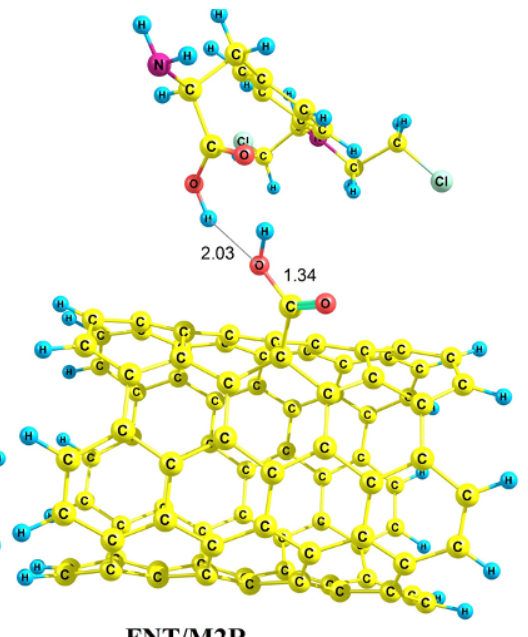

FNT/M2R

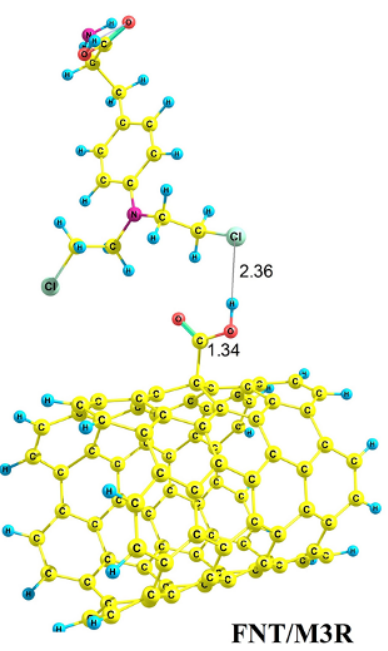

FNT/M3R

FIG. 2. Optimized geometries of FNT/M1-3R 

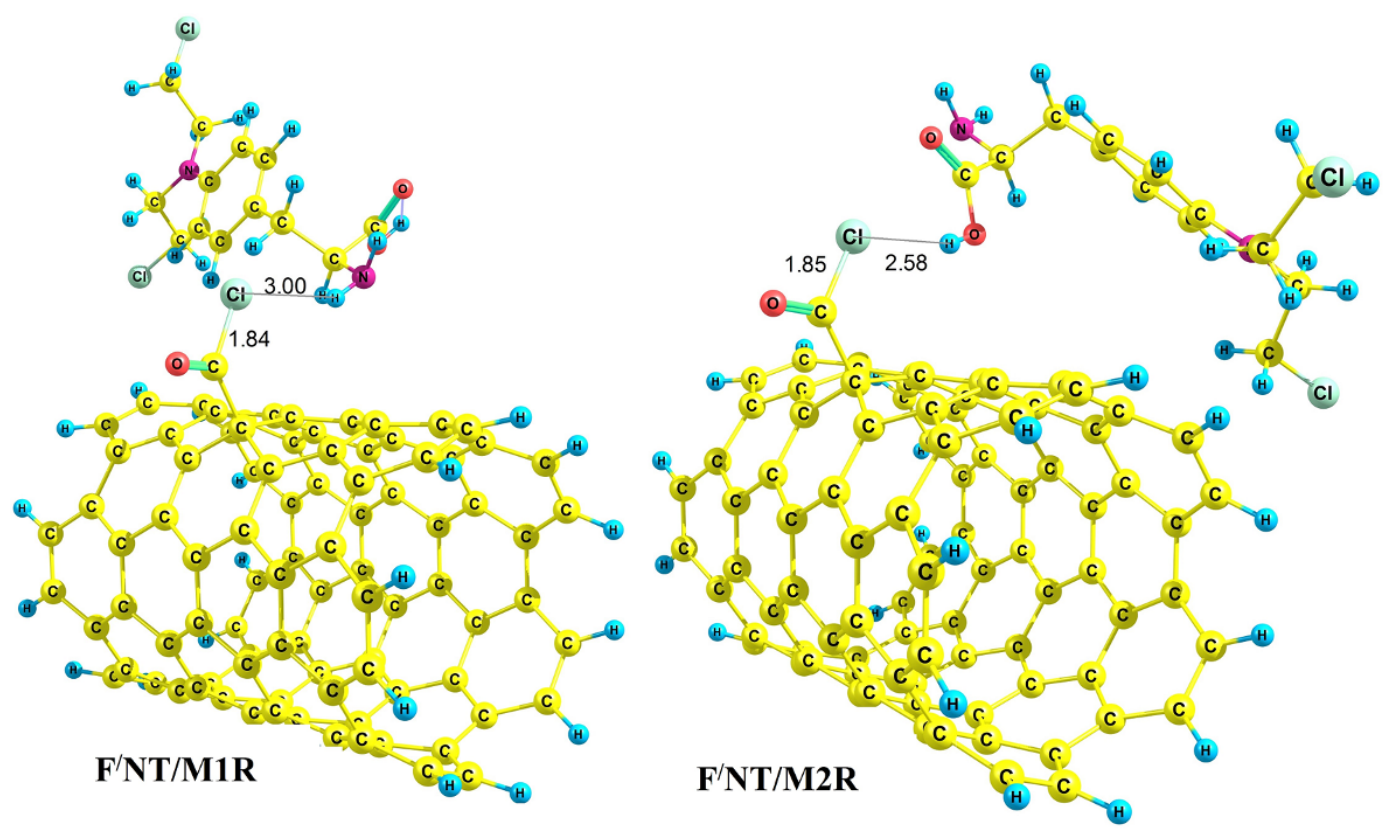

FIG. 3. Optimized geometries of $\mathrm{F}^{\prime} \mathrm{NT} / \mathrm{M} 1-2$

TABLE 1. Solvation and binding energies of different configurations $\left(\mathrm{kJ} \cdot \mathrm{mol}^{-1}\right)$

\begin{tabular}{cccc}
\hline Species & Solvation energy & Binding energy & Binding energy \\
\hline \hline M & -45.02 & Solution phase & Gas phase \\
FNT & -49.00 & & \\
\cline { 3 - 4 } FNT/M1R & -84.43 & -6.48 & -16.07 \\
FNT/M2R & -69.17 & -24.26 & -49.10 \\
FNT/M3R & -74.48 & -12.84 & -32.37 \\
F $^{\prime}$ NT/M1R & - & -2.74 & - \\
F $^{\prime}$ NT/M2R & - & -7.79 & - \\
\hline
\end{tabular}

Using the calculated $\Delta E_{s}$ of five species in Table 1, these binding energies are negative in gas and solution phases showing $\mathrm{M}$ drug is stabilized by FNT and $\mathrm{F}^{\prime} \mathrm{NT}$ surfaces. Among the 5 species, FNT/M1-3R are more stable than $F^{\prime}$ NT/M1-2R. Among the three species of FNT/M1-3R, the second one has more negative energy in gas and solution phases, denoting a stronger hydrogen bonding (from $\mathrm{OH}$ group).

Generally, for noncovalent interactions, comparison between FNT and $\mathrm{F}^{\prime} \mathrm{NT}$ indicates that using the first one is more favorable because of a stronger hydrogen bonding between $\mathrm{M}$ and $\mathrm{COOH}$ functionalized single wall carbon nanotube.

The solvation energies ( $\Delta E_{\text {solv }}$ ) of all structures have been calculated using the following equation:

$$
\Delta E_{\text {solv }}=E_{\text {sol }}-E_{\text {gas }}
$$

where $E_{g a s}$ and $E_{\text {sol }}$ represent the total energies in the gas and solution phases, respectively. The solvation energies of M, FNT, FNT/M1-3R have been shown in Table 1. Because of the negative values of solvation energies, this process is spontaneous. The calculated solvation energies show that $\mathrm{M}$ solubility increases in the vicinity of FNT. After the functionalization of $\mathrm{M}$ on FNT, solubility of $\mathrm{M}$ increases which is critical to the drug delivery systems. The important feature of $\mathrm{M}$ is in having $\mathrm{NH}_{2}, \mathrm{OH}$ and $\mathrm{Cl}$ groups, creating hydrogen bonds between FNT, solvent molecules and $\mathrm{M}$ drug. 
Table 2 represents the quantum molecular descriptors for $\mathrm{M}\left(\mathrm{H}_{2} \mathrm{O}, \mathrm{DMF}, \mathrm{GAS}\right)$, FNT $\left(\mathrm{H}_{2} \mathrm{O}, \mathrm{GAS}\right), \mathrm{F}^{\prime} \mathrm{NT}(\mathrm{DMF})$, FNT/M1-3R $\left(\mathrm{H}_{2} \mathrm{O}, \mathrm{GAS}\right)$ and $\mathrm{F}^{\prime} \mathrm{NT} / \mathrm{M} 1-2 \mathrm{R}(\mathrm{DMF})$. In Table 2, gap of energy between LUMO and HOMO $\left(E_{g}\right)$ was also evaluated. $E_{g}$ determines a more stable system.

TABLE 2. Binding energies $\left(\mathrm{kJ} \cdot \mathrm{mol}^{-1}\right)$ and quantum molecular descriptors $(\mathrm{eV})$ for optimized species

\begin{tabular}{|c|c|c|c|c|c|}
\hline Species & $E_{\mathrm{HOMO}}$ & $E_{\mathrm{LUMO}}$ & $E_{g}$ & $\eta$ & $\omega$ \\
\hline & & $\mathrm{H}_{2} \mathrm{O}$ & & & \\
\hline $\mathrm{M}$ & -5.37 & -0.24 & 5.12 & 2.56 & 1.53 \\
\hline FNT & -4.04 & -2.74 & 1.30 & 0.65 & 8.86 \\
\hline FNT/M1R & -4.05 & -2.76 & 1.29 & 0.65 & 8.96 \\
\hline FNT/M2R & -4.04 & -2.74 & 1.30 & 0.65 & 8.86 \\
\hline \multirow[t]{2}{*}{ FNT/M3R } & -3.92 & -2.73 & 1.19 & 0.60 & 9.26 \\
\hline & & GAS & & & \\
\hline $\mathrm{M}$ & -5.52 & -0.35 & 5.17 & 2.59 & 1.66 \\
\hline FNT & -3.90 & -2.59 & 1.31 & 0.65 & 8.04 \\
\hline FNT/M1R & -3.96 & -2.66 & 1.30 & 0.65 & 8.44 \\
\hline FNT/M2R & -3.92 & -2.62 & 1.30 & 0.65 & 8.21 \\
\hline \multirow[t]{2}{*}{ FNT/M3R } & -3.92 & -2.61 & 1.31 & 0.65 & 8.17 \\
\hline & & DMF & & & \\
\hline $\mathrm{M}$ & -5.37 & -0.24 & 5.12 & 2.56 & 1.54 \\
\hline $\mathrm{F}^{\prime} \mathrm{NT}$ & -4.07 & -2.82 & 1.26 & 0.63 & 9.46 \\
\hline $\mathrm{F}^{\prime} \mathrm{NT} / \mathrm{M} 2 \mathrm{R}$ & -4.09 & -2.83 & 1.25 & 0.63 & 9.57 \\
\hline $\mathrm{F}^{\prime} \mathrm{NT} / \mathrm{M} 3 \mathrm{R}$ & -4.09 & -2.84 & 1.25 & 0.63 & 9.62 \\
\hline
\end{tabular}

$\eta$ and $E_{g}$ of the $\mathrm{M}$ drug are higher than those of FNT/M1-3R and $\mathrm{F}^{\prime} \mathrm{NT} / \mathrm{M} 1-2 \mathrm{R}$, demonstrating the reactivity of $\mathrm{M}$ increases in the presence of $\mathrm{COOH}(\mathrm{COCl})$ functionalized NT. $\omega$ of $\mathrm{M}$ increases in the vicinity of $\mathrm{COOH}(\mathrm{COCl})$ functionalized NT, showing that $\mathrm{M}$ is an electron acceptor. The $\eta$ and $E_{g}$ values in FNT/ M1-2R are higher than $\mathrm{F}^{\prime} \mathrm{NT} /$ M1-2R, indicating $\mathrm{F}^{\prime} \mathrm{NT} / \mathrm{M}$ to be more reactive (less stable) compared to FNT/ M.

In the covalent functionalization, $\mathrm{NH}_{2}$ and $\mathrm{OH}$ groups attack the carbon atom of $\mathrm{COOH}$ or $\mathrm{COCl}$ to transfer their protons to the $\mathrm{OH}(\mathrm{Cl})$ group. We considered these four possible mechanisms for $\mathrm{F}\left(\mathrm{F}^{\prime}\right) \mathrm{NT} / \mathrm{M} 1-2 \mathrm{R}$. In $\mathrm{COOH}$ mechanism $\mathrm{OH}$ from FNT is substituted by $\mathrm{NH}(\mathrm{O})$ from $\mathrm{M}$ to give product $\mathrm{P}\left(\mathrm{P}^{\prime}\right) \mathrm{FNT}$. The optimized products $\left(\mathrm{P}\left(\mathrm{P}^{\prime}\right) \mathrm{FNT}\right)$ have been presented in Fig. 4.

Using reactant FNT/M1R and product PFNT, the transition state of this step was obtained (TS1 in Fig. 5). The bond lengths are presented in Figs. 2, 4 and 5.

Relative energies for all structures have been calculated in Table 3 by considering the zero value for electronic plus zero point energy $(E)$, enthalpy $(H)$ and Gibbs free energy $(G)$ of reactants $(\mathrm{FNT}+\mathrm{M})$. The activation energy $\left(E_{a}\right)$, activation enthalpy $\left(\Delta H^{\ddagger}\right)$ and activation Gibbs free energy $\left(\Delta G^{\ddagger}\right)$ for COOH/M1 mechanism are 200.53, 202.78 and $254.38 \mathrm{~kJ} \cdot \mathrm{mol}^{-1}$, respectively (Table 3 ).

Similar to COOH/M1 mechanism, using FNT/M2R and $\mathrm{P}^{\prime}$ FNT, the transition state (TS2 in Fig. 5) was obtained. $E_{a}, \Delta H^{\ddagger}$ and $\Delta G^{\ddagger}$ for $\mathrm{COOH} / \mathrm{M} 2$ mechanism are $125.41,129.02$ and $178.99 \mathrm{~kJ} \cdot \mathrm{mol}^{-1}$ respectively (Table 3). In room temperature, the activation energies of $\mathrm{COOH}$ mechanism are too high to occur.

In the other reactions for the covalent functionalization of $\mathrm{M}$ onto $\mathrm{COCl}$ functionalized carbon nanotube $(\mathrm{COCl}$ mechanism), FNT was firstly converted into alkyl chloride using SOCl2 ( $\left.\mathrm{F}^{\prime} \mathrm{NT}\right)$ [70]. M then reacts with $\mathrm{F}^{\prime} \mathrm{NT}$ to form covalent bond. $\mathrm{F}^{\prime} \mathrm{NT}$ is again converted to FNT in the presence of water. Therefore, this process should take place in a solvent such as DMF. In this mechanism, the attack of $\mathrm{NH}_{2}$ and $\mathrm{OH}$ of $\mathrm{M}$ to $\mathrm{Cl}$ in the $\mathrm{F}^{\prime} \mathrm{NT}$ forms products $\mathrm{PF}^{\prime} \mathrm{NT}$ and $\mathrm{P}^{\prime} \mathrm{F}^{\prime} \mathrm{NT}$, respectively (Fig. 6). 


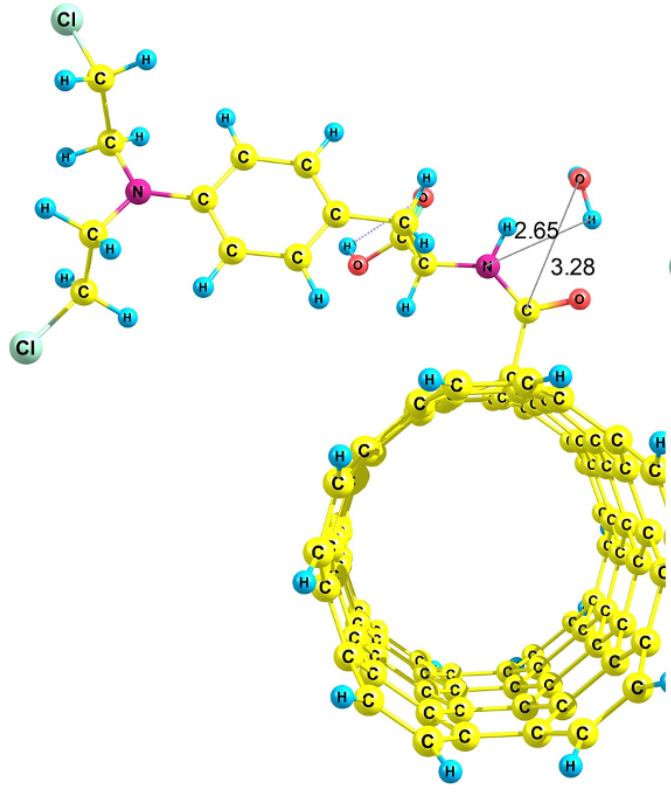

PFNT

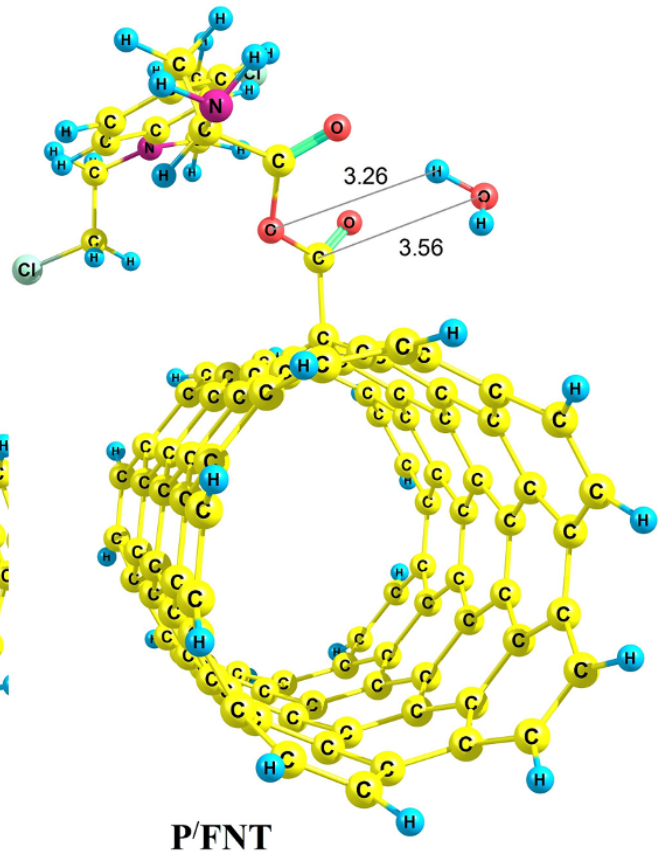

FIG. 4. Optimized geometries of PFNT and $\mathrm{P}^{\prime} \mathrm{FNT}$
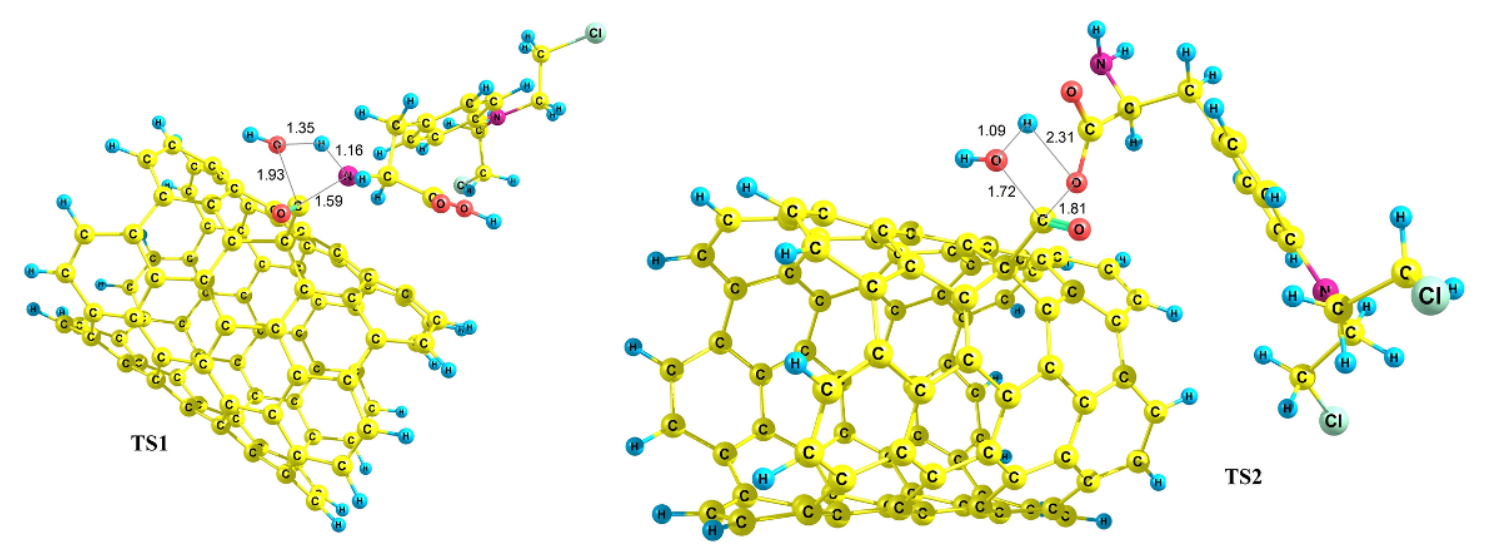

FIG. 5. Optimized geometries of TS1 and TS2

Using $\mathrm{F}^{\prime} \mathrm{NT} / \mathrm{M} 1 \mathrm{R}$ and $\mathrm{PF}^{\prime} \mathrm{NT}$, TS3 is optimized (Fig. 7). The bond lengths are represented in Figs. 3, 6 and $7 . E_{a}$, $\Delta H^{\ddagger}$ and $\Delta G^{\ddagger}$ for $\mathrm{COCl} / \mathrm{M} 1$ mechanism are $68.10,74.68$ and $95.24 \mathrm{~kJ} \cdot \mathrm{mol}^{-1}$, respectively (Table 3 ). Using reactant $\mathrm{F}^{\prime} \mathrm{NT} / \mathrm{M} 2 \mathrm{R}$ and product $\mathrm{P}^{\prime} \mathrm{F}^{\prime} \mathrm{NT}$, TS4 was obtained (Fig. 7). $E_{a}, \Delta H^{\ddagger}$ and $\Delta G^{\ddagger}$ for $\mathrm{COCl} / \mathrm{M} 2$ mechanism are 86.66 , 94.94 and $114.02 \mathrm{~kJ} \cdot \mathrm{mol}^{-1}$, respectively (Table 3).

The total $E_{a}$ for COCl/M1-2 mechanisms are lower than COOH/M1-2 mechanisms by 132.43 and $38.75 \mathrm{~kJ} \cdot \mathrm{mol}^{-1}$, respectively. Hence, for the covalent functionalization of CNT by M drug $\mathrm{F}^{\prime} \mathrm{NT}$ should be used.

\section{Conclusion}

Four configurations of noncovalent interactions of drug melphalan (M) onto FNT and $\mathrm{F}^{\prime} \mathrm{NT}$ were examined. The binding energies of $\mathrm{F}^{\prime} \mathrm{NT}$ are lower than those of FNT, denoting FNT/M configurations have more stability. The HOMO-LUMO energy gap and global hardness of FNT/M species are greater than those of $\mathrm{F}^{\prime} \mathrm{NT} / \mathrm{M}$ configurations species, showing the reactivity of $\mathrm{M}$ increases in the $\mathrm{F}^{\prime} \mathrm{NT} / \mathrm{M}$ species and its stability decreases.

Four covalent functionalization mechanisms of $\mathrm{M}$ onto FNT (COOH mechanism) and $\mathrm{F}^{\prime} \mathrm{NT}(\mathrm{COCl}$ mechanism) have been examined. $\mathrm{M}$ may bond to $\mathrm{FNT}$ or $\mathrm{F}^{\prime} \mathrm{NT}$ via $\mathrm{NH}_{2}$ and $\mathrm{OH}$ groups. The energy barriers of $\mathrm{COOH}$ mechanisms are higher than those of $\mathrm{COCl}$ mechanisms. Therefore, $\mathrm{COCl}$ mechanisms are suitable for the covalent functionalization. 
TABLE 3. Relative energies $\left(\mathrm{kJ} \cdot \mathrm{mol}^{-1}\right)$ for species in $\mathrm{COOH}$ and $\mathrm{COCl}$ mechanisms

\begin{tabular}{|c|c|c|c|}
\hline Species & E & $\mathrm{H}$ & $\mathrm{G}$ \\
\hline In water & \multicolumn{3}{|c|}{$\mathrm{COOH}$ mechanism } \\
\hline $\mathrm{FNT}+\mathrm{M}$ & 0.00 & 0.00 & 0.00 \\
\hline FNT/M1R & -6.48 & 0.00 & 26.38 \\
\hline TS1 & 200.53 & 202.78 & 254.38 \\
\hline PFNT & -9.07 & -2.57 & 23.79 \\
\hline FNT/M2R & -24.26 & -22.01 & 28.66 \\
\hline TS2 & 125.41 & 129.02 & 178.99 \\
\hline $\mathrm{P}^{\prime} \mathrm{FNT}$ & 49.24 & 51.77 & 102.44 \\
\hline In DMF & \multicolumn{3}{|c|}{$\mathrm{COCl}$ mehanism } \\
\hline $\mathrm{F}^{\prime} \mathrm{NT}+\mathrm{M}$ & 0.00 & 0.00 & 0.00 \\
\hline $\mathrm{F}^{\prime} \mathrm{NT} / \mathrm{M} 1 \mathrm{R}$ & -2.74 & 4.07 & 23.59 \\
\hline TS3 & 68.10 & 74.68 & 95.24 \\
\hline $\mathrm{PF}^{\prime} \mathrm{NT}$ & -16.96 & -11.43 & -3.55 \\
\hline $\mathrm{F}^{\prime} \mathrm{NT} / \mathrm{M} 2 \mathrm{R}$ & -7.79 & -0.90 & 18.52 \\
\hline TS4 & 86.66 & 94.94 & 114.02 \\
\hline $\mathrm{P}^{\prime} \mathrm{F}^{\prime} \mathrm{NT}$ & -22.58 & -17.20 & -9.41 \\
\hline
\end{tabular}
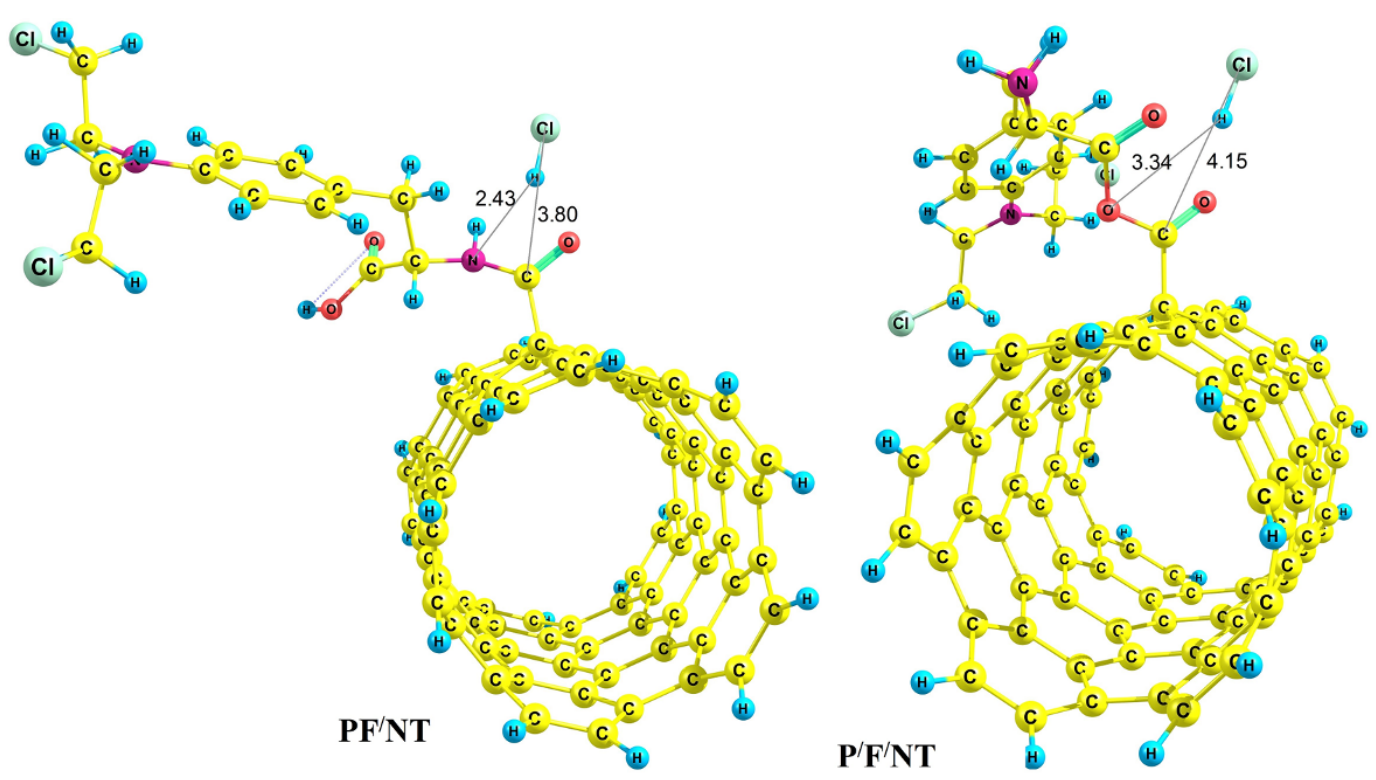

FIG. 6. Optimized geometries of $\mathrm{PF}^{\prime} \mathrm{NT}$ and $\mathrm{P}^{\prime} \mathrm{F}^{\prime} \mathrm{NT}$ 


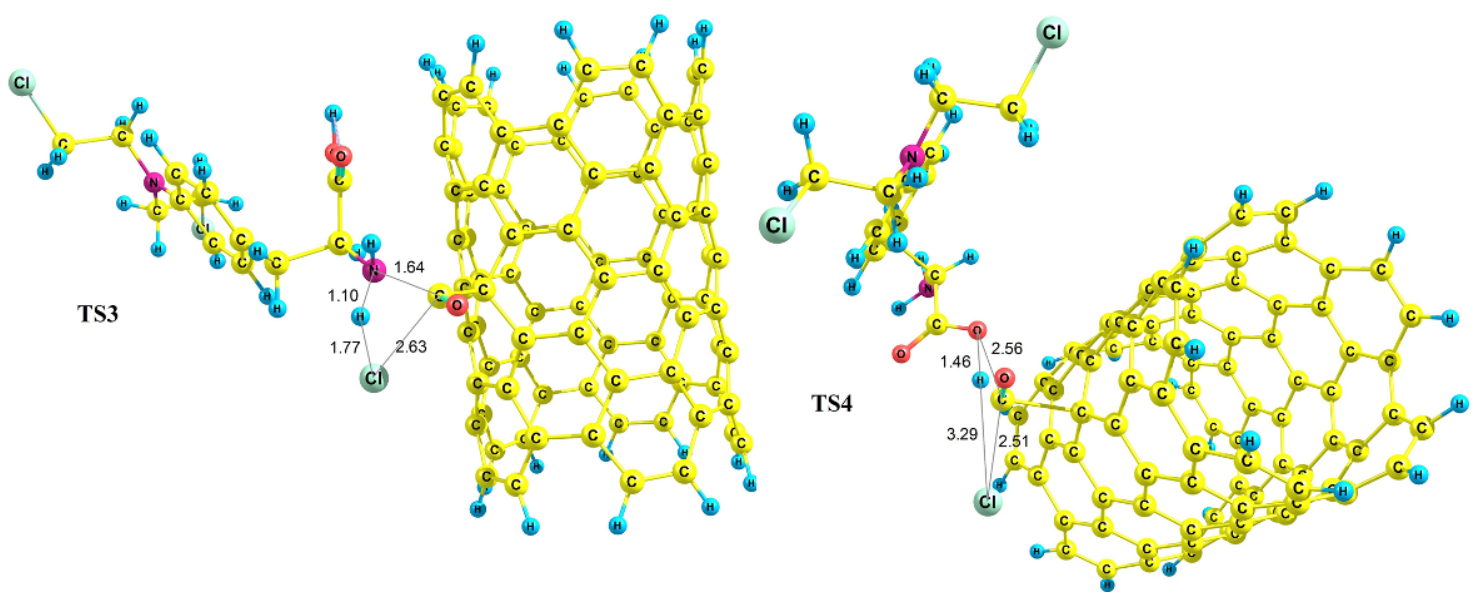

FIG. 7. Optimized geometries of TS3 and TS4

\section{References}

[1] Pennock G.D., Dalton W.S., et al. Systemic toxic effects associated with high-dose verapamil infusion and chemotherapy administration. $J$. Natl. Cancer Inst., 1991, 83 (2), P. 105-110.

[2] Lindley C., McCune J.S., et al. Perception of chemotherapy side effects cancer versus noncancer patients. Cancer pract., 1999,7 (2), P. $59-65$.

[3] Hughes G.A. Nanostructure-mediated drug delivery. Nanomedicine in Cancer, Pan Stanford, 2017, P. 47-72.

[4] Mitra S., Sasmal H.S., et al. Targeted drug delivery in covalent organic nanosheets (CONs) via sequential postsynthetic modification. J. Am. Chem. Soc., 2017, 139 (12), P. 4513-4520.

[5] Ramasamy T., Ruttala H.B., et al. Smart chemistry-based nanosized drug delivery systems for systemic applications: a comprehensive review. J. Controlled Release, 2017, 258, P. 226-253.

[6] Liu Q., Das M., Liu Y., Huang L. Targeted drug delivery to melanoma. Adv. Drug Deliv. Rev., 2018, 127, P. $208-221$.

[7] Chauhan A.S. Dendrimers for Drug Delivery. Molecules, 2018, 23 (4), 938.

[8] Marasini N., Haque S., Kaminskas L.M. Polymer-drug conjugates as inhalable drug delivery systems: A review. Curr. Opin. Colloid Interface Sci., 2017, 31, P. 18-29.

[9] Pattni B.S., Chupin V.V., Torchilin V.P. New developments in liposomal drug delivery. Chem. Rev., 2015, 115 (19), P. 10938-10966.

[10] Ghosh P., Han G., et al. Gold nanoparticles in delivery applications. Adv. Drug Deliv. Rev., 2008, 60 (11), P. 1307-1315.

[11] Arami H., Khandhar A., Liggitt D., Krishnan K.M. In vivo delivery, pharmacokinetics, biodistribution and toxicity of iron oxide nanoparticles. Chem. Soc. Rev., 2015, 44 (23), P. 8576-8607.

[12] Etebari N., Morsali A., Beyramabadi S.A. Structural and Mechanistic Studies of $\gamma-\mathrm{Fe}_{2} \mathrm{O}_{3}$ Nanoparticle as Capecitabine Drug Nanocarrier. Chinese J. Struc. Chem., 2018, 3, P. 375-382.

[13] Naghavi F., Morsali A., Bozorgmehr M.R. Molecular mechanism study of surface functionalization of silica nanoparticle as an anticancer drug nanocarrier in aqueous solution. J. Mol. Liq., 2019, 282, P. 392-400.

[14] Spencer D.S., Puranik A.S., Peppas N.A. Intelligent nanoparticles for advanced drug delivery in cancer treatment. Current opinion in chemical engineering, 2015, 7, P. 84-92.

[15] Bokarev A., Plastun I. Possibility of drug delivery due to hydrogen bonds formation in nanodiamonds and doxorubicin: molecular modeling. Nanosystems: Phys. Chem. Math., 2018, 9 (3), P. 370-377.

[16] Khorram R., Morsali A., et al. Mechanistic, Energetic and Structural Aspects of the Adsorption of Carmustine on the Functionalized Carbon Nanotubes. Chinese J. Struc. Chem., 2017, 10, 007

[17] John A.A., Subramanian A.P., et al. Carbon nanotubes and graphene as emerging candidates in neuroregeneration and neurodrug delivery. Int. J. Nanomedicine, 2015, 10, 4267.

[18] Kamel M., Raissi H., Morsali A., Shahabi M. Assessment of the adsorption mechanism of Flutamide anticancer drug on the functionalized single-walled carbon nanotube surface as a drug delivery vehicle: An alternative theoretical approach based on DFT and MD. Appl. Surf. Sci., 2018, 434, P. 492-503.

[19] d'Amora M., Giordani S. Carbon Nanomaterials for Nanomedicine. Smart Nanoparticles for Biomedicine, Elsevier, 2018, P. $103-113$.

[20] Mikheev I., Pirogova M., et al. Optimization of the solventexchange process for highyield synthesis of aqueous fullerene dispersions. Nanosystems: Phys. Chem. Math., 2018, 9 (1), P. 41-45.

[21] Shaki H., Morsali A., et al. Mechanistic, energetic and structural studies of single-walled carbon nanotubes functionalized with penicillamine. J. Serb. Chem. Soc., 2018, 83 (2), P. 167-179.

[22] Barnett C.J., Gowenlock C.E., et al. Spatial and contamination-dependent electrical properties of carbon nanotubes. Nano Lett., 2018,18 (2), P. 695-700.

[23] Kholmanov I.N., Magnuson C.W., et al. Optical, electrical, and electromechanical properties of hybrid graphene/carbon nanotube films. Adv. Mater., 2015, 27 (19), P. 3053-3059.

[24] Il'ina M., Il'in O., et al. The memristive behavior of nonuniform strained carbon nanotubes. Nanosystems: Phys. Chem. Math., 2018, 9 (1), P. 76-78.

[25] Abdalla S., Al-Marzouki F., Al-Ghamdi A.A., Abdel-Daiem A. Different technical applications of carbon nanotubes. Nanoscale Res. Lett., $2015,10(1), 358$. 
[26] Sozykin S., Beskachko V. Optical properties of defective carbon nanotube (7,7). Nanosystems: Phys. Chem. Math., 2018, 9 (1), P. 73-75.

[27] Cheng H.-M., Liu C., Hou P.-X. Field emission from carbon nanotubes. Nanomaterials Handbook, Second Edition, CRC Press, 2017, P. 255272.

[28] Ferreira F., Franceschi W., et al. Dodecylamine functionalization of carbon nanotubes to improve dispersion, thermal and mechanical properties of polyethylene based nanocomposites. Appl. Surf. Sci., 2017, 410, P. 267-277.

[29] Bocharov G., Egin M., Eletskii A., Kuznetsov V. Filling carbon nanotubes with argon. Nanosystems: Phys. Chem. Math., 2018, 9 (1), P. 85-88.

[30] Chandrasekhar P. CNT Applications in Drug and Biomolecule Delivery. Conducting Polymers, Fundamentals and Applications, Springer, 2018, P. 61-64.

[31] Meher J.G., Kesharwani P., et al. Carbon Nanotubes (CNTs): A Novel Drug Delivery Tool in Brain Tumor Treatment. Nanotechnology-Based Targeted Drug Delivery Systems for Brain Tumors, Elsevier, 2018, P. 375-396.

[32] Pham-Huy C., Dramou P., et al. Carbon Nanotubes Used as Nanocarriers in Drug and Biomolecule Delivery. Drug Delivery Approaches and Nanosystems, 1, Apple Academic Press, 2017, P. 163-212.

[33] Sciortino N., Fedeli S., et al. Multiwalled carbon nanotubes for drug delivery: Efficiency related to length and incubation time. Int. J. Pharm., 2017, 521 (1-2), P. 69-72.

[34] Karimi M., Solati N., et al. Carbon nanotubes part II: a remarkable carrier for drug and gene delivery. Expert Opin. Drug Deliv., 2015, 12 (7), P. 1089-1105.

[35] Zhang H., Hou L., et al. In vitro and in vivo evaluation of antitumor drug-loaded aptamer targeted single-walled carbon nanotubes system. Curr. Pharm. Biotechnol., 2014, 14 (13), P. 1105-1117.

[36] Unnati S., Shah R. Review: Nano carrier systems for cancer therapy. Int. J. Pharm. Technol., 2011, 3 (2), P. $927-946$.

[37] Mehra N.K., Palakurthi S. Interactions between carbon nanotubes and bioactives: a drug delivery perspective. Drug Discov. Today, 2016, 21 (4), P. 585-597.

[38] Mehra N.K., Jain K., Jain N.K. Pharmaceutical and biomedical applications of surface engineered carbon nanotubes. Drug Discov. Today, 2015, 20 (6), P. 750-759.

[39] Hampel S., Vittorio O., Cirillo G., Makharza S. Physiological and Clinical Considerations of Drug Delivery Systems Containing Carbon Nanotubes and Graphene. Drug Delivery Approaches and Nanosystems, 2, Apple Academic Press, 2017, P. $229-248$.

[40] You Y., Wang N., et al. Designing dual-functionalized carbon nanotubes with high blood-brain-barrier permeability for precise orthotopic glioma therapy. Dalton Trans., 2019, 48, P. 1569-1573.

[41] Samal S.K. Cancer and Carbon Nano Tubes: A Promising Hope of Future. Scientific Review, 2018 , 4 (7), P. $64-67$.

[42] Ménard-Moyon C. Applications of Carbon Nanotubes in the Biomedical Field. Smart Nanoparticles for Biomedicine, Elsevier, 2018, P. 83101.

[43] Feazell R.P., Nakayama-Ratchford N., Dai H., Lippard S.J. Soluble single-walled carbon nanotubes as longboat delivery systems for platinum (IV) anticancer drug design. J. Am. Chem. Soc., 2007, 129 (27), P. 8438-8439.

[44] Karimi-Maleh H., Tahernejad-Javazmi F., et al. A novel DNA biosensor based on a pencil graphite electrode modified with polypyrrole/functionalized multiwalled carbon nanotubes for determination of 6-mercaptopurine anticancer drug. Industrial \& Engineering Chemistry Research, 2015, 54 (14), P. 3634-3639.

[45] Liu Z., Sun X., Nakayama-Ratchford N., Dai H. Supramolecular chemistry on water- Soluble carbon nanotubes for drug loading and delivery. ACS Nano, 2007, 1 (1), P. 50-56.

[46] Wolski P., Nieszporek K., Panczyk T. Pegylated and folic acid functionalized carbon nanotubes as pH controlled carriers of doxorubicin. Molecular dynamics analysis of the stability and drug release mechanism. PCCP, 2017, 19 (13), P. 9300-9312.

[47] Lay C.L., Liu H.Q., Tan H.R., Liu Y. Delivery of paclitaxel by physically loading onto poly (ethylene glycol)(PEG)-graftcarbon nanotubes for potent cancer therapeutics. Nanotechnology, 2010, 21 (6), 065101.

[48] Samorì C., Ali-Boucetta H., et al. Enhanced anticancer activity of multi-walled carbon nanotubemethotrexate conjugates using cleavable linkers. Chem. Commun., 2010, 46 (9), P. 1494-1496.

[49] Razzazan A., Atyabi F., Kazemi B., Dinarvand R. In vivo drug delivery of gemcitabine with PEGylated single-walled carbon nanotubes. Mater. Sci. Eng.: C, 2016, 62, P. 614-625.

[50] Chae S., Kim D., et al. Encapsulation and Enhanced Delivery of Topoisomerase I Inhibitors in Functionalized Carbon Nanotubes. ACS Omega, 2018,3 (6), P. 5938-5945.

[51] Yi W., Zhang P., et al. Enhanced response of tamoxifen toward the cancer cells using a combination of chemotherapy and photothermal ablation induced by lentinan-functionalized multi-walled carbon nanotubes. Int. J. Biol. Macromol., 2018,120, P. $1525-1532$.

[52] Wang C., Li W. Preparation, characterization, and in vitro and vivo antitumor activity of oridonin-conjugated multiwalled carbon nanotubes functionalized with carboxylic group. Journal of Nanomaterials, 2016, 2016, 3439419.

[53] Karadas-Bakirhan N., Patris S., et al. Determination of the anticancer drug sorafenib in serum by adsorptive stripping differential pulse voltammetry using a chitosan/multiwall carbon nanotube modified glassy carbon electrode. Electroanalysis, 2016, 28 (2), P. 358-365.

[54] Haroun A., Amin H., El-Alim S.A. Immobilization and In vitro Evaluation of Soyasapogenol B onto Functionalized Multi-Walled Carbon Nanotubes. IRBM, 2018, 39 (1), P. 35-42.

[55] Facon T., Mary J.Y., et al. Melphalan and prednisone plus thalidomide versus melphalan and prednisone alone or reduced-intensity autologous stem cell transplantation in elderly patients with multiple myeloma (IFM 9906): a randomised trial. The Lancet, 2007, 370 (9594), P. 12091218.

[56] Horowitz M.E., Etcubanas E., et al. Phase II testing of melphalan in children with newly diagnosed rhabdomyosarcoma: a model for anticancer drug development. J. Clin. Oncol., 1988, 6 (2), P. 308-314.

[57] Lotfi M., Morsali A., Bozorgmehr M.R. Comprehensive quantum chemical insight into the mechanistic understanding of the surface functionalization of carbon nanotube as a nanocarrier with cladribine anticancer drug. Appl. Surf. Sci., 2018, 462 (34), P. 720-729.

[58] Saikia N., Deka R.C. Adsorption of isoniazid and pyrazinamide drug molecules onto nitrogen-doped single-wall carbon nanotubes: an ab initio study. Struct. Chem., 2014, 25 (2), P. 593-605.

[59] Chegini H., Morsali A., Bozorgmehr M., Beyramabadi S. Theoretical study on the mechanism of covalent bonding of dapsone onto functionalised carbon nanotubes: effects of coupling agent. Prog. React. Kinet. Mech., 2016, 41 (4), P. 345-355.

[60] Xu H., Li L., Fan G., Chu X. DFT study of nanotubes as the drug delivery vehicles of Efavirenz. Comput. Theor. Chem., 2018, 1131, P. 57-68. 
[61] Kamel M., Raissi H., Morsali A. Theoretical study of solvent and co-solvent effects on the interaction of Flutamide anticancer drug with Carbon nanotube as a drug delivery system. J. Mol. Liq., 2017, 248, P. 490-500.

[62] Shahabi D., Tavakol H. DFT, NBO and molecular docking studies of the adsorption of fluoxetine into and on the surface of simple and sulfur-doped carbon nanotubes. Appl. Surf. Sci., 2017, 420, P. 267-275.

[63] Naderi S., Morsali A., Bozorgmehr M.R., Beyramabadi S.A. Mechanistic, energetic and structural studies of carbon nanotubes functionalised with dihydroartemisinin drug in gas and solution phases. Phys. Chem. Liq., 2018, 56 (5), P. 610-618.

[64] Ketabi S., Rahmani L. Carbon nanotube as a carrier in drug delivery system for carnosine dipeptide: A computer simulation study. Mater. Sci. Eng.: C, 2017, 73, P. 173-181.

[65] Wong B.S., Yoong S.L., et al. Carbon nanotubes for delivery of small molecule drugs. Adv. Drug Deliv. Rev., 2013,65 (15), P. $1964-2015$.

[66] Frisch M., Trucks G., et al. Gaussian 09, Revision B. 01 [computer software]. Wallingford, CT, USA: Gaussian. Inc. Google Scholar, 2010.

[67] Tomasi J., Persico M. Molecular interactions in solution: an overview of methods based on continuous distributions of the solvent. Chem. Rev., 1994, 94 (7), P. 2027-2094.

[68] Coitino E.L., Tomasi J., Cammi R. On the evaluation of the solvent polarization apparent charges in the polarizable continuum model: a new formulation. J. Comput. Chem., 1995, 16 (1), P. 20-30.

[69] Parr R.G., Szentpaly L.v., Liu S. Electrophilicity index. J. Am. Chem. Soc., 1999, 121 (9), P. 1922-1924.

[70] Lin T., Bajpai V., Ji T., Dai L. Chemistry of carbon nanotubes. Aust. J. Chem., 2003, 56 (7), P. 635-651. 